\title{
ESTADO CONFESIONAL EN COSTA RICA: ALGUNOS DEBATES DESDE LA CONSTRUCCIÓN DE POLÍTICAS PÚBLICAS ${ }^{1}$
}

\section{CONFESSIONAL STATE IN COSTA RICA: SOME DEBATES FROM THE CONSTRUCTION OF PUBLIC POLICIES}

\author{
Priscilla Carballo Villagra*
}

\section{RESUMEN}

En este artículo se presenta de manera sintética la base política-ideológica, legal e histórica del financiamiento del Estado costarricense a la Iglesia católica y además, se plantean los montos de financiamiento que se asignan a la Iglesia en ese periodo para los cinco mecanismos institucionales en estudio. El trabajo de campo consistió en revisión de documentos institucionales $y$ entrevista a funcionarios $y$ funcionarias en las instituciones respectivas. Como principal conclusión del trabajo se plantea que esta relación de intercambio de obsequios entre la iglesia y el Estado se basa en un proceso de ritualización-bendición del poder político, sin embargo, es necesario ampliar el debate sobre la canalización de estos fondos como una reflexión de la política pública.

\section{PALABRAS CLAVE: IGLESIA Y ESTADO * IGLESIA CATÓLICA * POLÍTICA GUBERNAMENTAL * GASTO PÚBLICO}

\section{ABSTRACT}

This is a synthetic presentation of the political, ideological, legal and historical basis of the Costa Rican state's funding to the Catholic Church, and also the funding amounts assigned to the church from five institutional mechanism under study. The field work consisted in reviewing institutional documents and interviewing officials in the respective institutions. The main conclusion of the work is that this relationship of exchange of gifts between the church and the state is based on a process of ritualization-blessing of political power, however, it is necessary to broaden the debate on the channeling of these funds as a debate of public policy.

KEYWORDS: CHURCH AND STATE * CATHOLIC CHURCH * GOVERNMENT POLICY * PUBLIC EXPENDITURE

$1 \quad$ El presente artículo expone algunos resultados de la investigación titulada "Estado confesional en Costa Rica: implicaciones para las políticas públicas del financiamiento del estado a la iglesia católica 2014-2016", realizado desde el Centro de Investigación en Cultura y Desarrollo de la Universidad Estatal a Distancia (UNED), Costa Rica. 


\section{INTRODUCCIÓN}

El vínculo existente entre la Iglesia católica y el poder estatal es una construcción histórica de la cual se habla poco en los espacios de elaboración de política pública. Este vínculo que ha sido instaurado desde el artículo 75 de la Constitución Política, ha generado la existencia de un Estado confesional que desde su fundación ha direccionado de manera sostenida fondos a la Iglesia católica. En este artículo, se analizan las implicaciones en términos de política pública de la existencia de un Estado confesional en Costa Rica. Concretamente, interesa analizar el direccionamiento de fondos públicos que se realizan desde la institucionalidad, algunos de ellos amparados en el artículo 75 de la Constitución Política y otros, por medio de leyes específicas que permiten direccionar fondos. Se analizan cinco vías que se estudian en este documento:

$\diamond \quad$ Financiamiento por medio del Presupuesto General de la República, aprobado por Ministerio de Hacienda y Asamblea Legislativa.

$\diamond \quad$ Financiamiento para mantenimiento de templos por medio de la Oficina de Patrimonio del Ministerio de Cultura y Juventud (MCJ).

$\diamond \quad$ Financiamiento de centros de educación religiosos desde el Ministerio de Educación Pública (MEP).

$\diamond \quad$ Donaciones de instituciones estatales vía Ley nro. 7266 para la "Fundación para la Restauración de la Catedral Metropolitana $y$ otros Templos y Monumentos Católicos".

$\diamond \quad$ Exoneraciones de impuestos territoriales.

El trabajo de campo consistió en revisión documental, solicitud de información en las instituciones respectivas y finalmente, entrevista a funcionarios y funcionarias públicas. Para desarrollarlo, se presentan algunos debates teóricos que ayudan a entender el vínculo político estratégico entre ambos actores. Posteriormente, se realiza un breve repaso sobre cómo se ha construido el vínculo histórico entre el Estado costarricense y la Iglesia, seguidamente, se reseña la principal legislación que se ha desarrollado para que esto sea posible, también se plantea la dimensión económica, es decir, los montos asignados a la Iglesia en el periodo en estudio $y$, finalmente, se expresan algunas reflexiones del debate necesario sobre esta política de financiamiento en la Costa Rica contemporánea.

\section{LA BASE POLÍTICO-IDEOLÓGICA DEL FINANCIAMIENTO DEL ESTADO A LA IGLESIA CATÓLICA}

Un elemento central que se debe tener presente al hablar del Estado confesional en el caso costarricense, es que la Iglesia católica no es solamente una institución que remite a su carácter espiritual, es una institución que tiene otros dos elementos centrales, un sustento económico y un sustento político. En este apartado, se hace referencia a la construcción social de las religiones $y$ al proceso por medio del cual se ha logrado en muchos espacios desdibujar la base económica y política de este actor.

Los debates sobre la religión como campo de estudio han estado presentes desde los orígenes de la Sociología misma, y varios de los pensadores clásicos más relevantes, entre ellos, Weber y Durkheim, se encargaron de poner algunas de las bases del debate que se han complejizado hasta el día de hoy. Sus aportes ayudan a entender la relevancia de la religión y las iglesias como actores sociales que generan el apoyo de la institucionalidad estatal.

Weber (2001) en su clásico libro "La ética protestante y el espíritu del capitalismo" explica algunos elementos esenciales sobre el papel de las religiones, al plantearse la pregunta sobre las causas del éxito del protestantismo en Europa y su relación con el desarrollo del capitalismo. Para Weber, la base doctrinal de protestantismo que se fundamenta en la correcta conducta moral que él llama el "ascetismo laico", basado en el ahorro, el no gasto en lujos, y el trabajo como elemento de obra al servicio de dios, generó que se fuera gestando una forma de trabajo muy atinente con el naciente capitalismo. De esta forma, los bienes materiales se iban multiplicando y reinvirtiendo, con lo que se empieza a desarrollar lo que él llama una 
conducta "burguesa y racional", que vendrá a ser el inicio del "hombre económico moderno".

Al hacer estos planteamientos, el autor pone las bases de interés de la Sociología en el tema de las religiones, pero no solo para el análisis de cómo estos elementos espirituales impactaban la vida de las personas, sino las religiones como elementos centrales en la forma de estructuración de la vida en sociedad, e incluso como motor de ciertos sistemas económicos. Con este aporte, Weber sin duda posiciona la complejidad que implica el estudio de las religiones en el devenir de la disciplina.

Por su parte, Durkheim (2001) en su libro Las formas elementales de la vida religiosa toma como base una religión primitiva con la finalidad de explicar cómo funcionan estas en la vida de las personas y lo que él denomina "la naturaleza religiosa del hombre". El autor recuerda que el primer sistema de representación del ser humano ha sido el religioso, y por eso la filosofía y la ciencia han debatido con este sistema de manera permanente. Para el autor existen dos elementos constitutivos de las religiones: las creencias que son opiniones y los ritos que remiten a las acciones.

Para Durkheim (2001), las religiones van a articular un conjunto de creencias que van a ser compartidas por todos sus miembros (como la diferencia entre lo sagrado $y$ lo profano), $y$ van a instituir una serie de ritos que van a ser parte permanente de su accionar y estos van a ser los elementos más definitorios de una religión. Como parte de todo este debate, el autor plantea la siguiente definición de religión:

Llegamos pues a la definición siguiente: Una religión es un sistema solidario de creencias y de prácticas relativas a las cosas sagradas, es decir, separadas, interdictivas, creencias a todos aquellos que unen en una misma comunidad moral, llamada Iglesia, a todos aquellos que adhieren a ellas. El segundo elemento que entra de este modo en nuestra definición no es menos esencial que el primero; pues, mostrando que la idea de religión es inseparable de la idea de Iglesia, hace presentir que la religión debe ser cosa eminentemente colectiva (p. 66).
De varias maneras coincidente con esta definición de religión como construcción humana y social, Feuerbach (1971) en su libro La esencia del cristianismo. Crítica filosófica de la religión, plantea que el concepto que tiene el ser humano de dios es el concepto que tiene de sí mismo, y que proyecta todos esos valores, pensamientos y creencias que existen dentro de sí en un ente externo, de manera que las religiones permiten conocer las formas de pensar y las creencias de los pueblos sobre sí mismos. O planteado de otra forma, la religión representa un conflicto de la persona con sí misma al definir las características de dios en positivo y lo humano en negativo, es una visión sometida de sí mismo.

Sin duda esos aportes de Feuerbach (1971) en el tema ayudan a dilucidar el proceso individual y colectivo, mediante el cual se construye y sustentan las religiones en los diversos colectivos humanos, asimismo, como se verá más a delante, este proceso de construcción es el que le da fuerza a la Iglesia como institución al ponerla de muchas maneras más allá de lo humano y darle ese poder de desdibujar el componente material de su existencia.

Posiblemente, el autor que más ayuda a comprender el proceso social por medio del cual se van estructurando las religiones es Berger (1969) en su libro El dosel sagrado. Para una teoría sociológica de la religión. Según el autor, el concepto de religión está fuertemente articulado al de cultura, entendida esta como la totalidad de los productos creados por el ser humano. El proceso de construcción de la cultura consiste en que las personas externalizan pensamientos de la conciencia, los objetivan y legitiman, para posteriormente internalizarlos, no como construcciones propias sino como construcciones sociales avaladas por los colectivos, de manera que llegan a influir en la subjetividad $y$ ayudan a construirla.

Sin embargo, el autor aclara que esto se da en un proceso dialéctico, donde "el individuo continua siendo un coproductor del mundo social, y por ende de sí mismo" (Berger, 1969, p. 32). Estas construcciones subjetivas son objetivadas por la sociedad, de manera que 
son productos humanos que empiezan a tener poder sobre su productor.

Las construcciones objetivadas se convierten en instituciones sociales materiales 0 inmateriales, que empiezan a ejercer presión sobre las personas, en tanto esta objetivación es avalada por la colectividad, instituciones como la familia, la religión o la democracia son ejemplos claros de esto. Dichas construcciones explican una forma de orden legitimado $y$ en el caso concreto de la religión, le otorgan a esta un carácter sagrado como reproducción terrenal del orden divino, acá se encuentran entonces elementos del carácter político de las religiones dentro de la estructura social.

Es decir, existe un mandato divino de orden que se refleja en una estructura social existente, $y$ este se debe resguardar, por eso el peso de la autoridad divina y terrena es relevante para su mantenimiento. En el caso de las democracias modernas, ese orden $y$ autoridad en el plano político lo presentan las personas gobernantes para lo terrenal, y los sacerdotes para lo divino; son los guardianes de este, aunque en dos planos diferentes.

Con estos aportes de Berger (1969) en el tema, se comprende cómo las religiones han tomado un papel predominante en la vida de las personas, lo cual ha generado a su vez que las jerarquías de la institucional eclesial sean actores tan relevantes, incluso en la conformación de los estados. Por esta centralidad de las religiones como forma de explicación del orden social, se ha podido articular con el poder estatal, pues mutuamente se reafirman como formas de orden colectivo. Como plantea Bourdieu (2006) en su texto "Génesis y estructura del campo religioso":

La Iglesia contribuye al mantenimiento del orden político, $i$. e. al reforzamiento simbólico de las divisiones de este orden, en $y$ por el cumplimiento de su función propia, que es la de contribuir al mantenimiento del orden simbólico, i. e. (I) imponiendo e inculcando esquemas de percepción, de pensamiento y de acción objetivamente acordes con las estructuras políticas y adecuadas por ello para dar a esas estructuras la legitimación suprema que es la "naturalización", instaurando y restaurando el acuerdo sobre el ordenamiento del mundo a través de la imposición y la inculcación de esquemas de pensamiento comunes y de la afirmación o la reafirmación solemne de este acuerdo en la fiesta o la ceremonia religiosa, acción simbólica de segundo orden, que utiliza la eficacia simbólica de los símbolos religiosos para reforzar su eficacia simbólica reforzando la creencia colectiva en su eficacia; (II) comprometiendo la autoridad propiamente religiosa de la que dispone para combatir sobre el terreno propiamente simbólico las tentativas proféticas o heréticas de subversión del orden simbólico (p. 75).

Esta legitimación del orden establecido como bien lo plantea el autor, se hace evidente por medio de mecanismos simbólicos, por ejemplo, se recuerda que luego de la elección de la ex mandataria Laura Chinchilla, el obispo Francisco Ulloa la declara "hija predilecta de la virgen María" (La Nación, 24/10/2010), en un acto claro de unificación de poderes.

De manera recurrente, los grupos en el poder acuden al actor religioso como mediador de conflictos en lo político, en momentos complejos como la creación de las garantías sociales en Costa Rica, la mesa de negociación luego del conflicto por el "Combo del ICE", e incluso, en el debate nacional sobre el TLC, recurren a la Iglesia como santificadora y unificadora por medio de rituales como el anteriormente citado.

Ahora bien, en esta relación de afirmación mutua Estado-Iglesia, esta última como actor político, ha podido a lo largo de tiempo captar diferentes tipos de capitales que siguiendo los planteamientos de Bourdieu (1994), implican no solo un enorme capital simbólico, sino también un capital económico significativo, el cual proviene en parte del financiamiento estatal a partir de la declaratoria del estado como confesional. El Estado costarricense direcciona fondos a diferentes instancias de la estructura religiosa, pero no se sabe con claridad 
el costo de fondos públicos que esto conlleva, pues la Iglesia es un actor que se niega de manera permanente a evidenciar su dimensión económica.

Tal es el poder de legitimidad que posee esta institución, que ha logrado que se le asuma como un actor meramente espiritual, sin poder entrar en las discusiones a dilucidar elementos centrales de cómo funciona su operatividad económica y política. Como plantea Bourdieu (1994), el invisibilizar la lógica económica de la Iglesia, radica gran parte de su poder.

De hecho, la materialidad que sustenta la institución religiosa para el caso de Costa Rica ha implicado la utilización de un término que evidencia la necesidad de invisibilizar esta base económica. Se hace referencia al término "temporalidades" que es la forma de denominar los bienes materiales que tiene esta institución. El término remite a que son bienes temporales que se usan solo en el breve periodo de la vida terrenal, por eso su carácter temporal. Sin embargo, es bajo esta denominación que se maneja toda la base económica de la Iglesia católica, pues las Arquidiócesis de la Conferencia Episcopal tienen cédula jurídica bajo el nombre "Temporalidades de la Arquidiócesis..." y a partir de esta denominación es que se les direcciona dinero.

Esta lógica de "alquimia simbólica" del acto económico en acto religioso, es decir, en vez de denominarlo acumulación de dinero, llamarlo "bienes temporales de la vida terrenal", genera que sea sumamente difícil evidenciar aspectos del financiamiento del actor, pues son callados de manera sistemática por diferentes vías y se considera inapropiado hablar de estos temas. La importancia de este trabajo de investigación radica también en la posibilidad de romper con esta naturalización, con este silencio, y evidenciar el peso económico de esta institución y del costo que tiene en las finanzas públicas del país.

De esta forma, el proceso de legitimación de las religiones y concretamente de la Iglesia católica se ha instaurado en el imaginario social a partir de mecanismos propios de capital simbólico: el reconocimiento de feriados religiosos de pago obligatorio, el reconocimiento del matrimonio católico como acto civil, presencia de presidentes en misas del 2 de agosto, misas luego del proceso de elección presidencial, etc. (Maroto, 2012). Por esta razón, no es de extrañar la naturalización del acto de canalizar fondos públicos a la Iglesia, pues esta tiene presencia en muchos espacios de la vida social costarricense.

Maroto (2012) siguiendo los planteamientos de Bourdieu analiza varios momentos de la historia del país para plantear que el proceso de legitimación de la relación de la Iglesia $y$ el Estado se ha construido a partir de varios mecanismos:

$\diamond \quad$ Intercambio de obsequios y contraobsequios en donde los diferentes partidos en el poder han cuidado el vínculo con la Iglesia como un actor que legitima su accionar, $y$ para esto se da una dinámica de intercambios simbólicos para mantener dicho vínculo.

$\diamond \quad$ Legitimación carismática en este proceso se recurre a varios códigos como son el carisma, cordialidad y lenguaje religioso, en actos donde se combina el simbolismo religioso y el político, como las misas posteriores a la elección presidencial o las misas del 2 de agosto, en donde con el discurso religioso se hacen procesos de bendición de políticos y/o proceso políticos.

$\diamond \quad$ Legitimación tradicional en la que se recurre a códigos como el peso histórico de la tradición católica en la historia del país, el recurrir al evangelio o a insumos de la doctrina social de la Iglesia para legitimar decisiones políticas, las advertencias de las implicaciones de actuar de manera diferente al discurso cristiano, $y$ el discurso religioso de la figura del sacerdote como actor que ilumina al rebaño.

$\diamond \quad$ Legitimación racional en la que se alude a discursos consensuados como la democracia, entre otros.

A partir de este análisis que plantea la autora, se considera que si bien se remiten a actos fundamentalmente discursivos sobre los que se construye este vínculo, el tema de los 
obsequios y contraobsequios trascienden lo simbólico y tienen un componente económico en el cual la Iglesia recibe una cantidad importante de dinero como contraobsequio por este accionar de legitimación.

Este es un contraobsequio que se oculta detrás de todo este juego discursivo, el proceso de "obsequio y toma y daca" al que refiere Bourdieu (1994), y que, en el caso de estudio, afecta directamente las finanzas del Estado.

\section{LA BASE HISTÓRICA DEL FINANCIAMIENTO DEL ESTADO A LA IGLESIA CATÓLICA}

La relación de la estructura eclesial con el poder político está marcado por la historia misma de los estados en América Latina, con los procesos de invasión colonial venía incorporado todo un aparataje religioso político que se instaura hasta el día de hoy. Durante todo el proceso de desarrollo de los Estados latinoamericanos este actor ha tenido gran presencia en la toma de decisiones como aliado político estratégico. Para Mallimaci (2004), el proceso de relación del Estado con la Iglesia católica en América Latina ha pasado por tres fases:

$\diamond \quad$ La primera de 1880 a 1930 se generan las diferencias con los liberales por el poder capitalizado por la Iglesia en la incipiente política social, a partir de esto se les saca de ciertos espacios de poder, pero se negocia su permanencia en espacios como el educativo.

$\diamond \quad$ De 1930 a 1980 en el marco del desarrollo del Estado de bienestar, la Iglesia cumple un papel de mediador de procesos, como el citado proceso de las garantías sociales en Costa Rica, como forma de legitimación del poder de los partidos $y$ forma de contención del conflicto.

$\diamond \quad$ De 1980 a la fecha con los procesos de reformas neoliberales y la aparición de otras organizaciones religiosas evangélicas, se está dando un nuevo reacomodo de fuerzas, $y$ los discursos por un Estado laico están empezando a tener peso.

En Costa Rica, como lo plantean Payne, Vargas y Velázquez (1992), las expediciones de conquista inician en la zona del Pacífico provenientes desde Panamá entre 1519 y 1523, lideradas por Hernán Ponce de León, Juan de Castañeda, Gil Gonzáles Dávila y Francisco Fernández de Córdoba. Las segundas incursiones se dan en la zona del Atlántico costarricense hacia 1502, y entre 1510 y 1561 se hacen otras incursiones, pero el dominio de estas tierras es bastante más complejo que en el Pacífico. En el Valle Central, se da lo que estos autores denominan una conquista tardía, pues sucede hacia 1522-1524.

Desde estos primeros contactos junto con las labores de saqueo y previo a las acciones violentas de sometimiento, se utilizaba en las comunidades el llamado "Requerimiento" que era un instrumento jurídico leído a los indígenas (en latín y en español) donde se explicaba que debían someterse pacíficamente y adoptar la fe católica (Payne, Vargas y Velázquez, 1992). Es decir, desde las primeras acciones de invasión la fe católica fue utilizada como justificante de las acciones de sometimiento.

En el caso de Costa Rica, este proceso de evangelización se puede ver en la necesidad manifiesta en varias ocasiones del envío de frailes a estas tierras que consta en varios documentos históricos (Payne, Vargas y Velázquez, 1992). Además, en 1563 y 1566, se realiza la solicitud de bienes a España para tener decoradas las iglesias que a la fecha ya existían en el territorio.

En 1563, llegan misioneros franciscanos $y$ se asienta de manera permanente esta orden religiosa e inicia labores de evangelización, y a partir de 1573, con la creación de la Gobernación de Costa Rica ubicada en Cartago, se amplía la presencia de órdenes religiosas. Para finalizar, en el siglo XVI habían dos conventos en el país, el convento de San Francisco en Cartago y el convento de San Lorenzo en Esparza (Payne, Vargas y Velázquez, 1992).

El proceso de evangelización de las poblaciones indígenas durante el periodo colonial se llevó a cabo con la instauración de una figura de ordenamiento social que es "las reducciones", estas consistían en espacios organizados llamados distritos que en realidad eran agrupaciones de poblados de indígenas, que eran formas de segregación espacial y de control de 
estos. Cada una de estas reducciones estaban a cargo de un religioso o de un convento, que en principio eran los encargados de trasmitir la fe, y los indígenas además tenían la obligación de mantener al fraile o al convento. De manera que eran fundamentalmente unidades de control y explotación de la población.

Con la llegada de la independencia en 1821, se ve como el clero tuvo un rol protagónico en la creación del naciente Estado, en el proceso hubo un grupo del clero a favor de la independencia, $y$ otro en contra, fundado este último en el miedo a perder los privilegios logrados durante el régimen colonial. Al darse la declaración de independencia, se tiene una importante participación sacerdotal en el congreso, como señala Picado (1990):

En el primer congreso la participación sacerdotal se elevó a $32,14 \%$ del total, porcentaje superado en el congreso de $1832-1833$ donde el $45,45 \%$ de las sillas fueron ocupadas por sacerdotes. Diesiséis de los treinta y seis primeros congresos fueron presididos por sacerdotes (p.44).

Así, se comprende como desde los primeros años de vida independiente, la Iglesia supo ocupar un lugar vinculado al poder político para la legitimidad mutua y para mantener los beneficios que se venían construyendo desde el período colonial. Ejemplo de esto es que en 1852 se firma un concordato entre el arzobispo de la época que es Llorente y la Fuente junto a Juan Rafael Mora Porras. Esta firma era muy relevante pues se garantizaba la continuidad de varios beneficios que tenía la Iglesia desde la época colonial y por medio de esta acción se les daba respaldo.

\section{CUADRO 1}

BENEFICIOS OBTENIDOS POR AMBOS ACTORES EN LA FIRMA DEL PRIMER CONCORDATO ENTRE EL ESTADO COSTARRICENSE Y EL VATICANO EN 1852

\begin{tabular}{l|l}
\hline \multicolumn{1}{c|}{ BENEFICIOS OBTENIDOS POR LA IGLESIA } & \multicolumn{1}{c}{ BENEFICIOS OBTENIDOS POR EL ESTADO } \\
\hline $\begin{array}{l}\text { Legitimidad en el territorio, al ser reconocida como } \\
\text { la religión del Estado. }\end{array}$ & $\begin{array}{l}\text { Demuestra autonomía económica frente al estado del } \\
\text { Vaticano y evidencia que puede mantener la diócesis. }\end{array}$ \\
$\begin{array}{l}\text { Se garantiza ser la encargada de la educación } \\
\text { religiosa. }\end{array}$ & $\begin{array}{l}\text { Derecho de Patronato, es decir, que el presidente } \\
\text { tenía que estar de acuerdo en la designación de } \\
\text { los obispos y en el lugar geográfico de los nuevos } \\
\text { templos. }\end{array}$ \\
$\begin{array}{l}\text { La potestad del obispo para revisar libros y } \\
\text { prohibir su circulación si eran contrarios a sus } \\
\text { determinaciones. }\end{array}$ & $\begin{array}{l}\text { El presidente podría nombrar además a seis } \\
\text { canónigos del Cabildo. }\end{array}$ \\
$\begin{array}{l}\text { El Estado debe dotar de dinero a la Iglesia para } \\
\text { mantener al Obispo, el Cabildo, el Seminario y } \\
\text { algunos templos. }\end{array}$ & $\begin{array}{l}\text { El obispo y los clérigos debían prestar juramento de } \\
\text { fidelidad al gobierno. }\end{array}$ \\
$\begin{array}{l}\text { Exclusión del pago de impuestos de los terrenos } \\
\text { donde existen templos católicos. }\end{array}$ & $\begin{array}{l}\text { Además se incluye al final de cada misa una oración } \\
\text { para la protección de la república y el presidente. }\end{array}$
\end{tabular}

Fuente: Elaboración propia a partir de Sandí (2012).

Como se puede observar en el cuadro 1, para los intereses del presente estudio en la firma de este concordato están presentes dos acciones estatales de direccionamiento de fondos: el financiamiento vía presupuesto de la República y la exoneración de impuestos.

El motivo de la inclusión de estas medidas se origina en una disputa con el sector 
cafetalero, pues según plantea Sandí (2012) algunos sectores pagaban diezmo a la Iglesia católica, y el arzobispo Llorente y La Fuente estaba interesado en cobrar diezmo también a los cafetaleros; sin embargo, Mora Porras no estaba de acuerdo en hacer este cobro pues podía desincentivar esta actividad económica, por lo que decide pagar con fondos del Tesoro Nacional algunos rubros $y$ dejarlo garantizado en el Concordato firmado:

La disposición de subvencionar al Obispo, el Cabildo, el Seminario y algunas parroquias fue con la finalidad de suplir la derogación de los diezmos ejecutada paulatinamente por el gobierno de la República desde 1825. En lo concerniente a los diezmos la dotación que el gobierno central de la República se había comprometido a pagar por medio de decreto cxxv, del 15 de julio de 1853, en los artículos 1 y 2 quedó instaurado que Roma exoneraba a los católicos del país a no pagar el diezmo a la iglesia, permiso condicionado al compromiso del Estado de pagar diez mil pesos anuales. Los artículos 3 y 4, por su parte, aludían al modo de pago mensual después del 5 de octubre de 1853 (Sandí, 2012, p. 83).

Efectivamente, la base de las acciones fue un acuerdo entré la élite cafetalera, el gobernante y la Iglesia, para que el diezmo no saliera de los bolsillos de los primeros, sino del Tesoro Nacional. De acá en adelante se van a ir ampliando estos acuerdos, para llegar al entramado legal del financiamiento, que se verá en apartados siguientes.

Sin embargo, es importante señalar que esta relación entre Iglesia y el incipiente Estado costarricense no se da sin múltiples diferencias, pues a partir de 1880 con el posicionamiento de ideas liberales en algunos sectores del país, se pretende que el Estado tome más protagonismo, y se plantea el interés de tomar algunas atribuciones que a la fecha estaba desempeñando la Iglesia católica. En este contexto se dan las Leyes anticlericales de 1884 , las cuales no revierten de manera significativa estas relaciones.
Por el contrario y tal como plantea Sandí (2012) para inicios del siglo xx la relación entre la Iglesia y el Estado se basa en un proceso de legitimación mutua, prueba de esto es que en las cuatro constituciones de la República que se dan en el país en ese período (1847, 1859, 1869 y 1871), se designa al catolicismo como la religión oficial del Estado (García, 2012).

Esta legitimación se da de varias maneras, pues la Iglesia justificaba en sus discursos la importancia de la obediencia al poder del Estado, reproducía la imagen de ciudadano ejemplar a partir de la misma figura de los sacerdotes y además, destacaba su papel como actor en la cohesión social. Así a los gobernantes le resultaba muy beneficioso ese reforzamiento de principios del buen ciudadano.

Con la llegada de la crisis de 1929 que afectó fuertemente al país en años siguientes, fundamentalmente por la caída de los precios del café para exportación que en ese momento era vital para la economía, se empieza a generar un deterioro en las condiciones de vida en el país. Paralelo a esto, el ideario político costarricense se amplía pues empiezan a rondar en el país ideas de anarquismo y comunismo por diferentes vías. De esta forma, el panorama político del país se empieza a complejizar, $y$ fundamentalmente, se pone tenso por las precarias condiciones de un sector importante de la población, en el cual muchas de estas nuevas ideas políticas y organizativas empiezan a dejar huella.

Con la guerra civil de 1948, la Iglesia capitaliza logros, pues recobra un elemento central que había perdido con las leyes anticlericales de 1884: recupera las clases de religión en los colegios de secundaria y con esto un relativo control y presencia en el currículum educativo, elemento que va a ser central en la labor realizada por Monseñor Rúben Odio Herrera.

Posterior a la guerra del 48 , se inicia la creación de una serie de instituciones que van a cambiar el panorama industrial y laboral del país. Con esto surge dos aliados de la Iglesia que van a ocupar el poder en varias décadas y a consagrar el bipartidismo que gobernó al país: el Partido Liberación Nacional y el Partido Unidad Social Cristiana. Con ambos partidos, 
la Iglesia tuvo relaciones de cercanía y se generaron acuerdos.

Con la llegada a la silla episcopal de Monseñor Román Arrieta Villalobos en 1979 como quinto arzobispo de San José, se encuentra un periodo de relación entre la Iglesia y el Estado sin mayores contratiempos, pues las intervenciones de Román Arrieta siempre fueron llamados a la obediencia y el respeto a la autoridad, lo cual fue la base de sus discursos públicos.

En estas décadas, como analiza Maroto (2012), la participación de la Iglesia como legitimadora de las acciones estatales fue frecuente, incluso cuando se hacía referencia a temas muy complejos en coyunturas muy radicalizadas como la aprobación del TLC con Estados Unidos. A cambio de esto, los privilegios de la Iglesia se mantuvieron intactos $y$ en muchos casos a nivel material y simbólico estos privilegios se ampliaron, como se verá posteriormente en el apartado sobre legislación vinculada al direccionamiento de fondos del Estado a la Iglesia católica.

En 1985, se da la modificación al artículo 36 de la Constitución política en la que, si bien, se mantiene el hecho de que la religión católica es la oficial del Estado, se le prohíbe participar en procesos electorales, con lo que queda al menos formalmente subordinada al poder político.

Se puede citar en la historia reciente algunos enfrentamientos entre el Estado y la Iglesia por agendas concretas como los debates por las guías de educación para la sexualidad en 1988 (Fernández, 2010) o los derechos sexuales de las mujeres, estas discusiones nunca terminaron en grandes disputas y siempre ambos actores trataron de llevar la relación a buen puerto por interés mutuo.

Ahora bien, este enunciado constitucional de confesionalidad del Estado, se refuerza por varias vías, pero es necesario en este punto mencionar que otro mecanismo por medio del cual se concreta esta relación de la Iglesia y el Estado son los mencionados concordatos, que son otras figuras jurídicas que reafirman este vínculo entre estos dos actores colectivos.

El concordato ha sido el mecanismo utilizado para establecer las pautas generales de la relación entre la Iglesia católica y el Estado, siendo el único firmado en 1852. Según García (2012), se entiende el concordato como: "Aquel acuerdo suscrito entre un Estado determinado y la Santa Sede, que regula aspectos jurídicos determinado y beneficiosos para ambos suscriptores, para ajustarlos e incluirlos dentro del ordenamiento jurídico del Estado contrayente con la Santa Sede" (p. 184).

Para comprender la naturaleza jurídica del concordato es necesario aclarar que a la Iglesia católica se le concede la personalidad jurídica internacional, lo cual le permite realizar estos acuerdos que se reconocen como tratados internacionales.

El único concordato que ha sido firmado por Costa Rica es el citado en 1852, sin embargo, en el 2011 se anuncia que se va a iniciar la negociación para firmar un nuevo concordato. De hecho, en la visita de la exmandataria Laura Chinchilla al Vaticano en el 2012, se planteaba que facilitaría el proceso de dicha negociación, la cual se basó en la falta de información sobre los temas que se estarían negociando.

Sin embargo, para el 16 de mayo de 2016, se publica una noticia en el diario La Nación en la que se plantea, según declaraciones del canciller Manuel González, que la negociación del concordato se relegó, pues no es prioritario debido a que la agenda de asuntos internacionales está llena (Cambronero, 16/05/2016).

Así, como se ve en este recorrido histórico, siguiendo los planteamientos de Bourdieu (1994), la relación histórica de la Iglesia católica $y$ el estado costarricense ha sido una relación permanente de intercambio, que se institucionaliza por primera vez en el concordato firmado en 1852 donde ambas partes reciben bienes materiales y simbólicos, y que a lo largo de los años se complejiza conforme se van intercambiando más obsequios y contraobsequios.

Esta relación histórica es la más larga y compleja que tiene el Estado costarricense, pues como recuerda el señor Mauricio Granados, sacerdote y Secretario Adjunto de la Conferencia Episcopal, en entrevista realizada para este proceso de investigación: "Nosotros somos una organización anterior al Estado" (Granados, comunicación personal, noviembre de 2018). 
Se debe señalar que a partir de este breve repaso histórico, la presencia de dos características de la economía de los intercambios simbólicos que plantea Bourdieu (1994): "en primer lugar que entre un intercambio $y$ otro debe pasar un lapso de tiempo determinado que oculte que realmente es un proceso de intercambio, pues deben aparecer como hechos aislados, y lo segundo, es lo que denomina "el tabú de la explicitación" (p. 164); es decir, que nunca se debe hablar del dinero, por esto es muy importante que tanto la Iglesia como el Estado nunca nombren los montos trasferidos, $y$ solo se cite el artículo constitucional, o la ley que legitima el obsequio.

De esta forma, estos elementos de carácter histórico expuestos en el presente apartado permiten analizar el largo y complejo proceso del Estado confesional en Costa Rica y fundamentalmente, evidencian la articulación de ambos poderes para el mantenimiento del orden, siendo sin dudas claves para la comprensión del tema en estudio.

\section{LA BASE LEGAL DE LAS POLÍTICAS DE FINANCIAMIENTO DEL ESTADO A LA IGLESIA CATÓLICA}

Como se sabe a nivel formal, el financiamiento que se asigna a la Iglesia por parte del
Estado se basa en el artículo 75 de la Constitución Política que dicta lo siguiente:

Artículo 75.- La Religión Católica, Apostólica, Romana, es la del Estado, el cual contribuye a su mantenimiento, sin impedir el libre ejercicio en la República de otros cultos que no se opongan a la moral universal ni a las buenas costumbres.

Sin embargo, en este artículo constitucional no se establece claramente cuál es el monto asignado para este actor, $y$ ha sido a lo largo de un proceso de acuerdos políticos que se han plasmado actos administrativos. Pero además de este financiamiento vía presupuesto general de la república, se puede encontrar otras legislaciones que sustentan otras formas de canalización de fondos, por medio de tratos preferenciales para el financiamiento o la exoneración a ciertos actores, entre ellos, la Iglesia.

En relación a cada uno de los mecanismos que se analizaron en esta investigación, se realizó en el cuadro 2 una síntesis con la legislación o decretos que establecen este aspecto:

CUADRO 2

LEGISLACIÓN QUE PERMITE LA TRANSFERENCIA DE FONDOS PÚBLICOS A LAS TEMPORALIDADES DE LA IGLESIA CATÓLICA A PARTIR DE LAS CINCO VÍAS EN ESTUDIO

LEY O DECRETO

Ley nro. 6475

"Remodelación del Archivo

Arquidiocesano", 1980.

Ley nro. 7555

Patrimonio histórico-arquitectónico de Costa Rica, 1995.

Ley nro. 8791

Estímulo estatal de pago de salarios del personal docente $y$ administrativo de las instituciones privadas de enseñanza, 2009.
CONTENIDO

Art. 2. "El Poder Ejecutivo incluirá, en el próximo proyecto de ley de presupuesto, las partidas suficientes para dotar al Archivo de la Curia Metropolitana de personal técnico, que lo atienda y mantenga abierto al público".

Define el interés del Estado para preservar el patrimonio, por medio de estas declaratorias se financia la restauración de templos. En total, 60 edificaciones declaradas patrimonio pertenecen a las Temporalidades de la Iglesia católica y se puede financiar su restauración. Siendo la Iglesia la entidad con más bienes declarados patrimonio.

Establece pagos salariales por parte del MEP a personal docente que labora en instituciones educativas privadas, siendo la mayoría de las instituciones financiadas propiedad de congregaciones religiosas católicas. Estos nombramientos son denominados "funcionario público destacado en centros educativos privados". 


\section{LEY O DECRETO}

Decreto Ejecutivo nro. 33550

Reglamento del Otorgamiento de

Estímulos a la Iniciativa Privada en Materia de Educación por Parte del MEP, 2006.

\section{CONTENIDO}

Establece en su artículo 3 una tipología de estímulos que otorga el MEP, a instituciones educativas privadas, siendo la mayoría de las instituciones financiadas propiedad de congregaciones religiosas católicas. Los estímulos son:

“a) (Derogado por el artículo 20 del Reglamento a la Ley de Estimulo Estatal de Pago de Salarios del Personal Docente y Administrativo de las Instituciones Privadas de Enseñanza, aprobado mediante decreto ejecutivo $\mathrm{N}^{\circ} 36895$ del 10 de noviembre del 2011)

b) Transferencia de recursos económicos (dinero), con el fin de brindar soporte en algún proceso educativo de particular interés o el pago de educadores contratados en relación laboral común por el centro educativo privado, conforme el interés público.

c) Participación de los docentes del centro privado, en algún proceso de capacitación a educadores que organice o financie el Ministerio de Educación Pública, para sus servidores.

d) Participación de la comunidad estudiantil de un centro privado, en actividades culturales o de promoción educativa (tales como ferias científicas, etc.), que organice el Ministerio de Educación dentro del Sistema Educativo Público.

e) Prestamo o arrendamiento de instalaciones educativas propiedad del Ministerio de Educación Pública.

f) Cualesquiera otras modalidades de estímulo que se consideren oportunas y sean previamente autorizadas por la Contraloría General de la República para su utilización".

Ley nro. 7157

Ley de Creación de la Ciudad de los Niños, 1990.

Establece que el Estado debe cubrir los salarios del director y funcionarios docentes $y$ administrativos-docentes de esta institución. La Ciudad de los Niños pertenece a la Conferencia Episcopal de Costa Rica.

Ley nro. 6238

Ley de operación del Colegio agropecuario de San Carlos, 1998.

Estado asume los costos totales de operación y funcionamiento del Colegio Agropecuario de San Carlos y de la Escuela Técnica Agrícola e Industrial que son parte de este colegio. Estas dos instituciones pertenecen a la Conferencia Episcopal de Costa Rica.

Ley nro. 7266

Autorización a instituciones descentralizadas y empresas públicas del Estado para hacer Autoriza a las instituciones descentralizadas y a las empresas públicas del Estado, para que hagan donaciones en favor de la "Fundación para la restauración de la Catedral Metropolitana y otros Templos y Monumentos Católicos".

donaciones a Fundación para

restauración de Catedral

Metropolitana y otros templos $y$

monumentos católicos y empresas

privadas a deducir impuesto sobre la renta, 1991.

Ley nro. 7509

Impuesto sobre Bienes Inmuebles $y$ su reforma Ley 7729,1995.
Define como inmuebles no afectados por el impuesto los inmuebles pertenecientes a iglesias y organizaciones religiosas que se dediquen al culto. Así como los bienes de las temporalidades de la Iglesia Católica: la Conferencia Episcopal de Costa Rica, la Arquidiócesis y las diócesis.

Fuente: Elaboración propia a partir de revisión de la legislación. 
Este proceso de existencia y ampliación de una legislación que permite el direccionamiento de fondos se ha creado por medio de acuerdos políticos, pues las leyes son aprobadas en la Asamblea Legislativa. En el proceso de investigación que se realizó con la revisión de expedientes legislativos, se puede constatar el apoyo de bancadas legislativas del PLN y del Pusc para la aprobación de estas legislaciones.

De esta manera, se puede evidenciar que la cercanía de ambos actores permitió presentar proyectos legislativos que generaban que iniciativas eclesiales de diferente tipo fueran creadas con una asignación de fondos públicos que cubrían totalmente su manutención. Además, se evidencia la relevancia social y política del actor que cuenta con el apoyo de estos partidos para sus iniciativas.

Es tal la relevancia de este capital jurídico acumulado por la Iglesia, que en la entrevista realizada al señor Mauricio Granados (sacerdote y Secretario Adjunto de la Conferencia Episcopal), se menciona de manera recurrente las legislaciones respectivas que garantizan esa potestad de direccionamiento de fondos, incluso, inicia esta conversación planteando lo siguiente referido al artículo 75 de la Constitución: "La iglesia considera que ella no es quien tiene que velar por ese cumplimiento constitucional porque es un deber constitucional del estado, si a alguien no le gusta que cambie la constitución" (Granados, comunicación personal, noviembre de 2018).

De esta forma, el uso de la figura abstracta y particular del término las temporalidades de la Iglesia católica, permite la canalización de una importante cantidad de fondos por parte del Estado y es la legalidad la que formaliza este mecanismo, pues como plantea Bourdieu (1994), el capital jurídico "es una forma objetivada y codificada del capital simbólico" (p.108). Así, las responsabilidades por estas asignaciones de fondos públicos se diluyen en la trama burocrática-jurídica.

\section{EL RESULTADO ECONÓMICO DEL FINANCIAMIENTO DEL ESTADO A LA IGLESIA CATÓLICA}

Una vez que se analizaron los diferentes elementos que conforman la concreción de la política estatal de direccionamiento de fondos desde el Estado hacia la Iglesia católica, se pueden exponer los montos estimados para el período en estudio que resultan de estos acuerdos históricos. A continuación, se presenta en el cuadro 3 , una síntesis sobre los montos asignados a la Iglesia católica para los tres años en estudio. Es importante aclarar que para dos de las vías de financiamiento estudiadas no se pudo tener los datos respectivos. 


\section{CUADRO 3 \\ MONTO TOTAL DE FONDOS PÚBLICOS TRANSFERIDOS A LAS TEMPORALIDADES DE LA IGLESIA CATÓLICA PARA EL PERÍODO 2014, 2015 Y 2016 \\ POR LAS CINCO VÍAS EN ESTUDIO}

\begin{tabular}{|c|c|c|c|}
\hline VÍA DE FINANCIAMIENTO & $\begin{array}{c}\text { MONTO TOTAL } \\
\text { ASIGNADO PARA EL } \\
\text { AÑO } 2014\end{array}$ & $\begin{array}{c}\text { MONTO TOTAL } \\
\text { ASIGNADO PARA EL } \\
\text { AÑO } 2015\end{array}$ & $\begin{array}{c}\text { MONTO TOTAL } \\
\text { ASIGNADO PARA EL } \\
\text { AÑ̃ } 2016\end{array}$ \\
\hline Dirección de Educación Privada, MEP & 2019540779 & 1565870278 & 2570579730 \\
\hline Presupuesto General de la República & 315000000 & 465000000 & 17500000 \\
\hline Oficina de Patrimonio, MCJ & 94700000 & 195000000 & 244377725 \\
\hline $\begin{array}{l}\text { Donaciones de instituciones estatales por la } \\
\text { Ley nro. } 7266 \text { Fundación para la Restauración } \\
\text { de la Catedral Metropolitana y otros Templos y } \\
\text { Monumentos Católicos. }\end{array}$ & No se obtienen datos & No se obtienen datos & No se obtienen datos \\
\hline Exoneraciones de impuestos territoriales & No se obtienen datos & No se obtienen datos & No se obtienen datos \\
\hline TOTAL ANUAL & 2429240779 & 2225870278 & 2814957455 \\
\hline
\end{tabular}

Fuente: Elaboración propia a partir de información del MEP-Departamento de Educación Privada (información vía correo electrónico), Asamblea Legislativa-Departamento de Análisis Presupuestario (información vía correo electrónico), Ministerio de Cultura-Centro de Investigación y Conservación del Patrimonio Cultural (Oficio CICPC-1831-2017).

En el caso de la Ley 7266 denominada "Autorización a instituciones descentralizadas y empresas públicas del Estado para hacer donaciones a Fundación para restauración de Catedral Metropolitana y otros templos y monumentos católicos y empresas privadas a deducir impuesto sobre la renta", de la Dirección General de Hacienda, respondieron que no tienen estos datos y que si los tuvieran amparados en el Código de Normas y Procedimientos Tributarios, no podrían brindarlos.

Mientras que en el caso de la Ley Impuesto sobre Bienes Inmuebles Ley 7509 y su reforma Ley 7729, que exonera de dicho impuesto a los bienes de la Iglesia católica, dado que muchos de los bienes de esta Iglesia son de larga data, no se cuenta con estimaciones del valor real de las propiedades, por lo tanto, no es viable tener datos de las estimaciones de lo que el Estado costarricense deja de percibir por la exoneración de este impuesto. Para las restantes vías, sí se pudo obtener los datos respectivos $y$ se presentan en el cuadro 3 con las respectivas sumatorias anuales.

De esta forma, se evidencia para algunas de las vías en estudio, el costo anual transferido a la Iglesia católica, se observa que de manera constante se canalizan sumas de entre dos mil doscientos millones de colones y dos mil ochocientos millones de las arcas del Estado para las temporalidades de la Iglesia católica o congregaciones en el país.

Sin duda, el MEP es la institución que gira la cantidad más significativa de fondos a partir de las 4 legislaciones que le permiten direccionar fondos a centros educativos privados propiedad de la Conferencia Episcopal o de diferentes congregaciones religiosas; seguido de los fondos girados vía Presupuesto General de la República. 
Quedaría pendiente conocer cuánto se canaliza hacia la Fundación para la Restauración de la Catedral Metropolitana y otros Templos y Monumentos Católicos, y cuánto dinero le deja de ingresar a las arcas del Estado por la exoneración de impuestos territoriales para dimensionar el tema, pero se tienen datos relevantes para la discusión. Con estos elementos claros, entonces, en el apartado siguiente se puede dar algunos aportes para la política pública.

Ahora bien, en este punto surge la pregunta de cuál es la posición de la Conferencia Episcopal de Costa Rica frente a este direccionamiento de fondos, en primer lugar, como ha sido señalado en apartados anteriores, se plantea que se basa en el planteamiento constitucional del deber del Estado de financiar a la Iglesia, pero además, según la entrevista realizada al sacerdote Mauricio Granados:

Nosotros admitimos que hay fondos públicos que se asignan a la iglesia católica cuando entran a ser administrados $y$ depositados $y$ ejecutados por una persona jurídica eclesiástica, la Conferencia Episcopal las temporalidades o cada una de las diócesis, de lo contrario no estamos hablando en realidad de fondos que financian a la iglesia católica (Granados, comunicación personal, noviembre de 2018).

De esta forma, a partir de la entrevista realizada, esta instancia no reconoce este direccionamiento como financiamiento, pues sostienen, por ejemplo, que en el caso del MEP, si bien las personas trabajan en centros educativos de las diferentes congregaciones religiosas, son funcionarios del Ministerio y este es quien les paga. Desde su lógica, entonces también los fondos recibidos para conservación del patrimonio no es direccionamiento de fondos, en tanto ellos son escogidos por tener bienes arquitectónicos muy antiguos, y no por ser Iglesia. De esta forma, para este actor los únicos fondos que reconoce que son canalizados en tanto Iglesia son los del Presupuesto General de la República.

Sobre este particular, se considera que el asumir la Iglesia católica como un actor más que participa en igualdad de condiciones frente a otros, no es muy realista dado el proceso histórico y político que se han analizado en apartados anteriores. Además no existe ningún otro actor privado que reciba un aporte del Estado $\tan$ cuantioso, por lo que se considera que se da un proceso de alquimia simbólica que pretende negar estos actos económicos de intercambio, pues como plantea Bourdieu (1994):

La empresa religiosa es una empresa con una dimensión económica que no puede confesarse como tal $y$ que funciona en una especie de negación permanente de su dimensión económica: hago un acto económico, pero no quiero saberlo; lo llevo a cabo de tal modo que puedo decirme y decirles a los demás que no constituye un acto económico $-y$ solo puedo resultar creíble para los demás si lo creo yo mismo- (p. 189).

Con la presentación de estos datos se empieza a romper con la naturalización de esta empresa religiosa, pues permite dimensionar el costo de un Estado confesional católico para las finanzas públicas del país. Con estos elementos, es posible profundizar sobre el debate pendiente que existe de estas acciones en tanto políticas públicas.

\section{EL ESTADO CONFESIONAL EN COSTA RICA COMO UN DEBATE DE POLÍTICA PÚBLICA}

La decisión estatal de financiar la Iglesia católica es un debate relevante de política pública, pues siguiendo los planteamientos de $\mathrm{Pa}$ llares (1988), estas son actividades materiales o simbólicas que gestionan las autoridades públicas para la contención de los conflictos. Estas pueden ser elementos materiales (recursos, programas, proyectos, subsidios, exoneraciones) o bien, pueden ser acciones simbólicas (reconocimiento, valoraciones, etc., a ciertos actores o actitudes sociales).

En el caso que interesa en este artículo, se encuentran ambos tipos de acciones: simbólicas como ya se ha mencionado en los rituales permanentes de legitimación entre el actor religioso y el actor político, y elementos materiales 
con la canalización anual de montos que están entre los $\$ 2200000000$ y $\$ 2800000000$ de las arcas del Estado para las temporalidades de la Iglesia católica o congregaciones religiosas en el país.

Es decir, se evidencia una relación de intercambio de legitimación entre ambos, el estado costarricense financia en buena medida el accionar de las instituciones de la Iglesia: su archivo, sus escuelas, la restauración de sus edificaciones, pero ¿qué recibe a cambio de esto? Pues recibe legitimación en períodos de conflicto y una serie de mecanismos de ritualización-bendición del poder político. En un país donde toda la población ya no es necesariamente católica, el peso simbólico de la Iglesia sigue siendo tal que este financiamiento se mantiene y se amplía en la medida de las posibilidades. Ningún partido quiere pagar el costo político electoral que implica una ruptura con el actor religioso por un eventual recorte.

En esta relación de intercambios, la Iglesia católica además recibe un control relativo en áreas que supuestamente tienen que ver con temas sensibles a la fe católica en la legislación. En la historia reciente, se ha visto de manera recurrente la inacción del Estado costarricense en temas que pueden implicar una ruptura con la jerarquía eclesial, pues siguiendo los planteamientos de Oszlak y O'donell (1995), en el análisis de las políticas públicas, tanto las acciones que se desarrollan desde la institucionalidad estatal como las omisiones que se tienen, son temas relevantes para el análisis; por ejemplo, en el caso de la fertilización in vitro, se puede analizar la inacción estatal, como una intencionalidad política de ignorar un tema que genera conflictos, de manera que existe una estrategia estatal: acción por omisión.

Ahora bien, en la discusión de un eventual recorte de estos montos transferidos a la Iglesia católica, surgen la siguiente interrogante ¿la Iglesia católica solo puede financiar estas instituciones con el apoyo del Estado o tendrá recursos propios para hacerlo? Esta pregunta es relativamente difícil de contestar, pues no se puede acceder a las cuentas de la Conferencia Episcopal o de las congregaciones. Sin embargo, se han dado varias situaciones sociales que pueden dar algunas aproximaciones y se exponen a continuación.

En 1998, la Conferencia Episcopal compra el $21 \%$ de las acciones del grupo Sama por medio de Servicios Pastorales S.A. y en el 2012, una empresa panameña compra el 25\% de las acciones de la Conferencia Episcopal, este monto según una noticia publicada en el periódico La Nación (30/05/2012): “Con base en los estados financieros del grupo, este porcentaje equivale a una participación en el capital social de Sama superior a los $\$ 6.450$ millones. Sin embargo, el monto final de la operación no trascendió".

Además, parecería que la Conferencia Episcopal maneja importante cantidad de excedentes pues en el pasado ha sido investigada por intermediación financiera, como recuerda esta misma nota de prensa:

Desde entonces, la relación tuvo momentos convulsos. Entre el 2002 y 2010, las quejas de un grupo de inversionistas hicieron aflorar una supuesta intermediación financiera ilegal de la Conferencia Episcopal, que consistía en tomar recursos propios y de particulares e invertirlos en Grupo Sama, además de hacer prestamos. (La Nación, 30/05/2012).

De estos elementos generales, se desprende que efectivamente la Conferencia Episcopal tiene una importante cantidad de excedentes que reinvierte en diferentes escenarios económicos de "grandes ligas", por lo que es importante reflexionar si efectivamente este dinero existente en la estructura eclesial como excedentes, no se podía invertir en sus obras sociales, en lugar de que el Estado se las continúe financiando. Ante esta pregunta, el señor Mauricio Granados aunque no responde directamente la posibilidad de asumir directamente estas inversiones con fondos propios, responde lo siguiente:

Hay que distinguir uno es los fondos de la Conferencia Episcopal que es una persona jurídica aparte y otra cosa son los fondos de las diócesis y otra cosa de las organizaciones religiosas las congregaciones 
que tiene total autonomía, y ellos son los que deciden como invierten sus fondos. Los fondos de la Conferencia Episcopal tienen dos finalidades principales: uno es el sostenimiento del régimen del clero que es el subsidio que la Conferencia Episcopal da a los sacerdotes mayores de 65 años que en este momento está en 500 dólares verdad, y el mantenimiento del seminario que es el proyecto educativo propio de la formación de los futuros sacerdotes que conlleva un costo bastante elevado. Efectivamente como fondos privados la Conferencia Episcopal los invierte básicamente en esos proyectos, no hay otros, $y$ bueno el funcionamiento propio de este edificio de la sede y proyectos propios además del espectro de la asistencia social a través de Cáritas. Pero en este momento todas nuestras inversiones están en el sistema bancario nacional (Granados, comunicación personal, noviembre de 2018).

Como segundo elemento, vale la pena preguntarse, por ejemplo, si es necesario que una institución como el MEP financie, por diferentes vías, proyectos de congregaciones religiosas por montos anuales que van desde los \$1 565870278 a los $\$ 2019540779$, solo en los tres años del período en estudio, o si bien, sería mejor invertirlos en los colegios públicos ya existentes ubicados en esas mismas zonas, o también, invertir estos montos en mejorar el sistema de becas para la educación existente.

Es central recordar que las políticas públicas son debates sobre temas relevantes en la agenda pública, y fundamentalmente sobre la forma como se direccionan los fondos para atender las diferentes problemáticas sociales. Vale la pena empezar a discutir a qué actores sociales se les canaliza fondos, y qué forma de inversión de esos fondos tienen más beneficios para la colectividad. De manera que es importante analizar si lo más estratégico es financiar iniciativas privadas aisladas, o mejorar el sistema público existente. Pues las políticas públicas implican la forma por la que el grupo concibe $y$ actúa frente a las necesidades y son, por tanto, una forma de modelar la sociedad.

Finalmente, se debe recordar que en todo proceso de concreción de una política pública, existe un elemento que va a marcar las prioridades de la agenda, y es el tema presupuestario, ya que la decisión de cómo, dónde y por qué se asignan los recursos es una pugna histórica. Por esto, en el presente proyecto se le da un lugar al tema presupuestario, pues la decisión sostenida de financiar a la Iglesia católica, va a evidenciar el interés de un grupo de mantener la relación histórica de obsequios y contraobsequios financiados con fondos públicos, $y$ hacerlos parecer como decisiones beneficiosas para la colectividad, como recuerda Bourdieu (1994):

La doxa es un punto de vista particular, el punto de vista de los dominantes, que se presenta y se impone como punto de vista universal; el punto de vista de quienes dominan dominando el Estado y que han construido su punto de vista en tanto que punto de vista universal estableciendo el Estado (p. 121).

Cuestionar esta doxa con argumentos, datos e investigación en estos temas es más que necesario en la actual coyuntura. En un contexto nacional de crisis fiscal en donde se están planteando recortes en temas tan importantes como la educación y se están definiendo prioridades de gasto, vale la pena preguntarse si es necesario seguir financiando estas alianzas de élite.

\section{REFERENCIAS}

Berger, P. (1969). El dosel sagrado. Para una teoría sociológica de la religión. Buenos Aires, Argentina: Amorrortu Editores.

Bourdieu, P. (1994). Razones prácticas: sobre la teoría de la acción. Barcelona, España: Editorial Anagrama.

Bourdieu, P. (2006). Génesis y estructura del campo religioso. Relaciones. Estudios de Historia y Sociedad, 17 (108), 29-83. Recuperado de http://www.redalyc.org/ pdf/137/13710803.pdf

Cambronero, N. (16/05/2016). "Costa Rica relega negociación de un concordato con 
el Vaticano". La Nación. Recuperado de https://www.nacion.com/el-pais/ politica/costa-rica-relega-negociacion-de-un-concordato-con-el-vaticano/5AYUHKFMSZGEPLMLYJFAE3IO $\mathrm{VQ} /$ story/

Chinchilla reabre a obispos puertas de Casa Presidencial. (24/10/2010). La Nación. Recuperado de https://www.nacion. com/archivo/chinchilla-reabre-aobispos-puertas-de-casa-presidencial/XK7NVY6P4FFC7JPWSDMBTK $\mathrm{XSXY/story/}$

Conferencia Episcopal vende participación en Grupo Sama. (30/05/2012). Periódico La Nación. Recuperado de https://www. nacion.com/archivo/conferencia-episcopal-vende-participacion-en-grupo-sama/ ADTAP72BPFGN3AKRDC4PU7ASNY/ story/

Durkheim, E. (2001). Las formas elementales de la vida religiosa. México D.F, México: Editorial Coyoacán.

Fernández, A. (2010). Influencia de la iglesia católica en la construcción de representaciones sociales sobre la sexualidad: un análisis de las políticas de educación integral de la expresión de la sexualidad humana del Ministerio de Educación Pública en el período 2000-2009. (Tesis para optar por el grado de licenciatura en sociología). Universidad de Costa Rica. San José, Costa Rica.

Feuerbach, L. (1971). La esencia del cristianismo: crítica filosófica de la religión. Buenos Aires, Argentina: Editorial Claridad.

García, R. (2012). La Iglesia católica como sujeto de derecho internacional: implicaciones jurídicas del establecimiento de un estado Laico; y el concordato como mecanismo de protección para la iglesia. (Tesis para optar por el grado de Licenciatura en Derecho). Universidad de Costa Rica, San José, Costa Rica.
Mallimaci, F. (2004). Catolicismo y liberalismo: las etapas del enfrentamiento por la definición de la modernidad religiosa en América Latina. En J.P. Bastian (coord.), La modernidad religiosa. Europa latina y América Latina en perspectiva comparada. México D.F, México: Fondo de Cultura Económica.

Maroto, A. (2012). Los procesos de construcción de la legitimidad en las relaciones estado-iglesia católica en Costa Rica, 2007-2010. (Tesis para optar por el grado de máster en sociología). Universidad de Costa Rica. San José, Costa Rica.

Oszlak, O y O'Donnell, G. (1995). Estado y políticas estatales en América Latina: hacia una estrategia de investigación. Redes, 2 (4), 99-128

Pallares, F. (1998). Las políticas públicas: el sistema político en acción. Revista Estudios Políticos 62, 141-162.

Payne, E, C. Vargas y C. Velázquez (1992). Breve historia de la iglesia católica en Costa Rica, 1502-1992. San José, Costa Rica: Centro de Investigaciones Históricas, Escuela de Historia, Universidad de Costa Rica.

Picado, M. (1990). La Iglesia costarricense entre el pueblo y el Estado: de 1949 a nuestros días. San José, Costa Rica: Editorial Guayacán.

Sandí, J. (2012). Estado e Iglesia Católica en Costa Rica 1850-1920: en los procesos de control del espacio geográfico y la creación de un modelo costarricense. Heredia, Costa Rica: Editorial Universidad Nacional.

Weber, M (2013). La ética protestante y el espíritu del capitalismo. Barcelona, España: Ediciones Península.

Fecha de ingreso: $23 / 08 / 2019$ Fecha de aprobación: 13/02/2019 
